\title{
Prevention of Esophageal Damage During Ablation of Atrial Fibrillation by the Esophagus Mechanical Deviation
}

\author{
Prevenção de Dano Esofágico Durante Ablação de Fibrilação Atrial por Desvio \\ Mecânico do Esôfago
}

Enrique Indalécio Pachón Mateos ${ }^{1,2,{ }^{*},}$, José Carlos Pachón Mateos ${ }^{1,2,3}$, Ricardo Carneiro Amarante ${ }^{1,2}$, Carlos Thiene Cunha Pachón², Tasso Júlio Lobo², Tomás Guillermo Santillana Peña², Juán Carlos Zerpa Acosta ${ }^{2}$, Juán Carlos Pachón Mateos ${ }^{1,2,3}$, Felipe Ortêncio ${ }^{2}$, Christian Higuti1,2

ORCID IDS

Pachón-M EO (D) https://orcid.org/0000-0001-7509-0731

Pachón-M JC (D) https://orcid.org/0000-0002-5111-488X

Amarante RC (D) https://orcid.org/0000-0002-7181-8198

Pachón CTC (iD) https://orcid.org/0000-0003-3943-4722

Lobo TJ (D) https://orcid.org/0000-0002-2801-1903

\begin{abstract}
Atrial fibrillation is the most prevalent arrhythmia in the world population. Despite the use of antiarrhythmics, it is difficult to control clinically, causing symptoms and mainly generating risk of a thromboembolic event. Since 1998, by means of radiofrequency ablation, the treatment of atrial fibrillation has completely changed, but together with this important evolution complications from this ablative treatment technique have also started. In addition to the pulmonary vein stenosis caused by the ablation and later corrected with the change in the technique, atrioesophageal fistulas appeared due to the application of radiofrequency in the posterior wall of the left atrium. This wall is very close $(0.5 \mathrm{~cm}$ on average) to the esophagus, which facilitates the formation of the fistula that leads to the death of almost 100\% of the affected patients, despite the various treatment measurements already developed. To avoid this serious complication, several authors have created techniques to protect the esophagus including its mechanical deviation to a region opposite to the radiofrequency application, taking advantage of its mobility and easiness of handling. The mechanical deviation of the esophagus has proven to be the simplest, cheapest and most efficient way to protect this organ from radiofrequency thermal damage during atrial fibrillation ablation.
\end{abstract}

KEYWORDS: Catheter ablation; Atrial fibrillation; Atrioesophageal fistula; Mechanical esophageal deviation; Thermal protection of the esophagus.

\author{
Peña TGS (DD https://orcid.org/0000-0001-5795-9827 \\ Acosta JCZ (D https://orcid.org/0000-0001-7436-2299 \\ Pachón-M J (D) https://orcid.org/0000-0003-4410-8753 \\ Ortencio F (D) https://orcid.org/0000-0003-1805-0420 \\ Higuti C (D) https://orcid.org/0000-0003-3820-8600
}

\section{RESUMO}

A fibrilação atrial é a arritmia de maior prevalência na população mundial. Apesar do uso de antiarrítmicos, é de difícil controle clínico, ocasionando sintomas e principalmente gerando risco de um evento tromboembólico. A partir de 1998, por meio da ablação por radiofrequência, o tratamento da fibrilação atrial mudou completamente, porém junto a essa importante evolução também iniciaram as complicações advindas dessa técnica de tratamento ablativo. Além das estenoses das veias pulmonares causadas pela ablação e posteriormente corrigidas com a mudança da técnica, surgiram as fístulas átrio-esofágicas, devido à aplicação de radiofrequência na parede posterior do átrio esquerdo. Esta parede está bem próxima (0,5 cm em média) do esôfago, facilitando a formação da fístula que leva à morte quase 100\% dos pacientes acometidos, apesar das diversas medidas de tratamento já desenvolvidas. Para evitar essa grave complicação, vários autores criaram técnicas para proteger o esôfago incluindo seu desvio mecânico para uma região oposta à da aplicação de radiofrequência, aproveitando a sua mobilidade e facilidade de abordagem. O desvio mecânico do esôfago tem se mostrado a forma mais simples, barata e eficiente de proteger esse órgão da lesão térmica da radiofrequência durante a ablação da fibrilação atrial.

PALAVRAS-CHAVE: Ablação por cateter; Fibrilação Atrial; Fístula atrioesofágica; Desvio mecânico do esôfago; Proteção térmica do esôfago.

1.Universidade de São Paulo - São Paulo (SP), Brazil

2.Hospital do Coração - Serviço de Eletrofisiologia, Marcapasso e Arritmias - São Paulo (SP), Brazil

3.Instituto Dante Pazzanese de Cardiologia - Serviço de Marcapasso - São Paulo (SP), Brazil

Received: Jan. 28, 2020 | Accepted: Feb. 18, 2020

*Correspondence author: epachon@usp.br

Section Editor: José Tarciso Medeiros de Vasconcelos 


\section{INTRODUCTION}

The treatment of atrial fibrillation (AF) by catheter was described in 1998. Haïssaguerre ${ }^{1}$ described at that time that the triggers of atrial fibrillation were located inside the pulmonary veins $(\mathrm{PVs})$, in muscle bands from the atrial walls that penetrated these veins in a disorganized and random way. The application of radiofrequency within the PVs resulted in high incidence of stenosis and recurrence of arrhythmia².

As a consequence, the technique was modified and the target of ablation by radiofrequency $(\mathrm{RF})$ changed from the interior of the ostia to the antrum of $\mathrm{PVs}^{3}$. In addition, in order to increase the success rate, the blocking lines started to be created by RF in the posterior wall of the left atrium (LA) connecting the PVs. These locking lines on the posterior wall now configure a new challenge, as they could superheat the esophagus and cause thermal damage to this organ.

Catheter ablation of AF using different energy sources has become routine in most electrophysiology services due to better control of sinus rhythm when compared to antiarrhythmic drug therapy ${ }^{4}$. The pillar of the procedure is the isolation of $\mathrm{PVs}^{5}$. However, to improve results, several of these services started to use an extended approach to perform ablations, mainly in persistent forms of AF, implying the mapping and ablation of fractionated atrial electrograms $(\mathrm{FAEs})^{6}, \mathrm{AF}$ nests ${ }^{7}$, in background tachycardia $(\mathrm{BKT})^{8.9}$, as well as the creation of additional blocking lines ${ }^{10}$, in addition to the standard isolation of $\mathrm{PVs}^{5}$.

In addition to RF ablation, new energy sources have been made available (cryoablation, laser and ultrasound) as well as technically more elaborate catheters, which are capable of producing deeper lesions, creating the potential risk of damaging structures near the left atrium (LA), particularly the esophagus ${ }^{11}$.

One of the greatest concerns and possible limitations during the procedure is the warming of the esophagus, which can occur when the RF is being released into in the LA posterior wall. As a consequence, erosions (esophagitis) and ulcers are described, ranging from 2.9 to $47 \%{ }^{12}$ and atrioesophageal fistula (AEF), which is fortunately rare $^{13}$.

Atrioesophageal fistula has been described in patients undergoing surgical $\mathrm{AF}$ ablation ${ }^{14}$ and in patients undergoing catheter AF ablation using radiofrequency or cryoablation ${ }^{15}$.
Although the incidence of AEF is $0.1-0.25 \%{ }^{16-18}$, this complication increases the mortality rate by 80 to $100 \%$, being the second most frequent cause of death (16\%) related to the AF ablation procedure, behind only the acute cardiac tamponade ${ }^{19,20}$. The data available in the literature suggest that the occurrence of EAF appears to be independent of operator experience ${ }^{21}$.

Although several strategies are being developed to avoid thermal damage to the esophagus, they still occur and have been reported in the literature ${ }^{13,22}$.

The objective of this article is to review the fundamental aspects of esophageal thermal lesions, their complications, and which techniques are currently being used to prevent them.

\section{ANATOMICAL CORRELATION BETWEEN ESOPHAGUS AND LEFT ATRIUM}

The middle esophagus is a fibromuscular tube $25 \mathrm{~cm}$ long and only $2 \mathrm{~cm}$ wide. The esophagus position is often closer to the left PV ostia compared to the right PV ostia ${ }^{23,24}$. According to Cury et al. ${ }^{25}$, the mean transverse diameter of the LA in contact with the esophagus is $18.9 \pm 4.4 \mathrm{~mm}$, while the mean distance between the two structures is $1.9 \pm 0.7 \mathrm{~mm}$ (Fig. 1 ).

Regarding the innervation, the anterior vagal trunk passes externally to the pericardium, from 2.5 to $6.5 \mathrm{~mm}$ from the posterior wall of the left atrium or pulmonary veins $^{26}$. Another very important point is that both irrigation and esophageal innervation occur from the outer portion (adventitia) to the innermost portion of its wall (mucosa). Thus, any injury to the outer portion of the anterior wall has a high potential to compromise both irrigation and esophageal innervation, and may determine several unwanted consequences.

\section{Risk factors}

There are some risk factors mentioned in the literature that contribute to the formation of atrioesophageal fistula, such as presence of esophageal ulcer; larger diameter of LA; low body mass index (BMI); prolonged application of $\mathrm{RF}$ or lines overlapped on the posterior wall of the LA; use of deflectable sheaths, $8 \mathrm{~mm}$ catheters, orogenic or nasogastric probes or tubes; general anesthesia; maximum RF power $(W)$ on the posterior wall of the LA; and high 


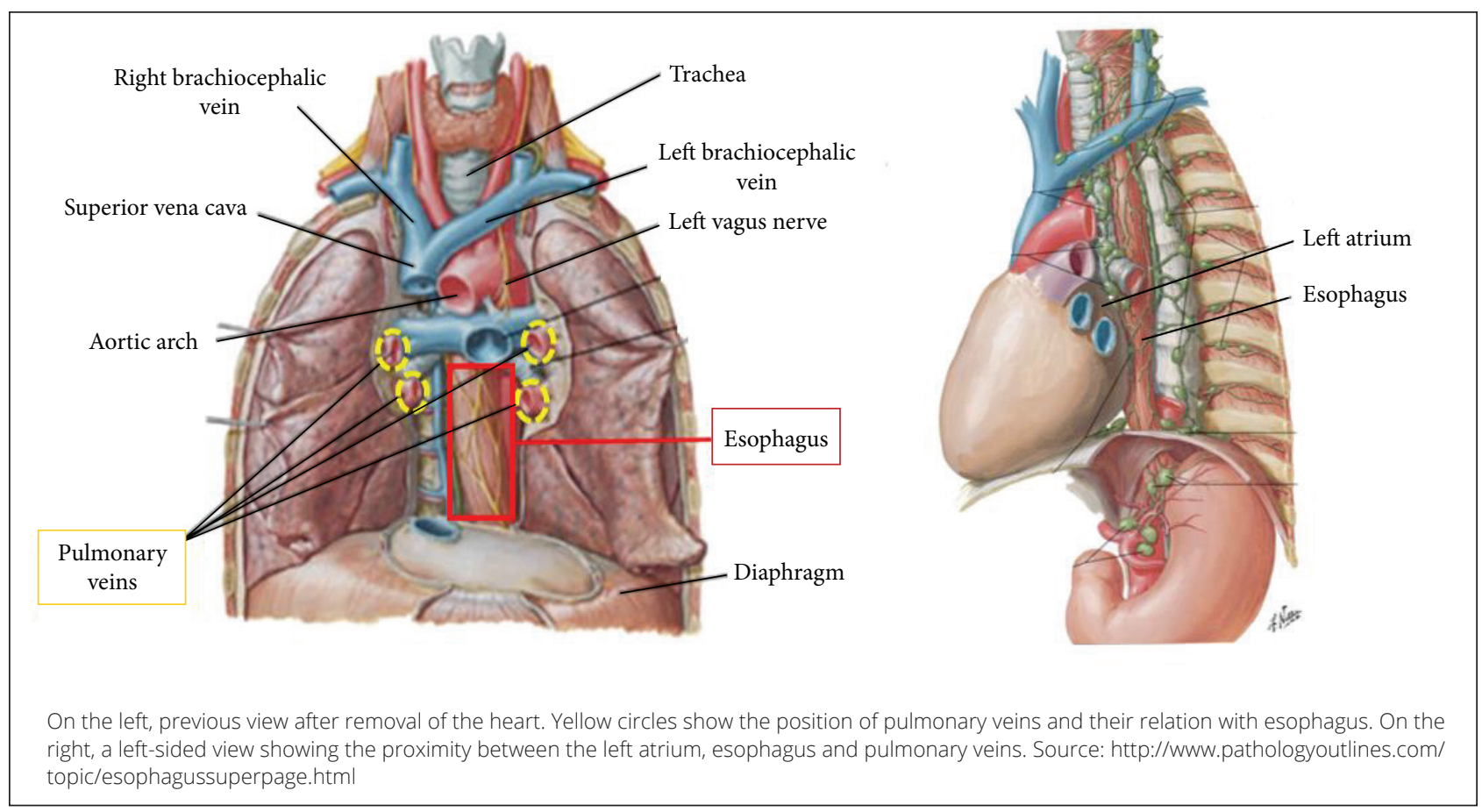

Figure 1. Anatomical relation between the esophagus and the left atrium.

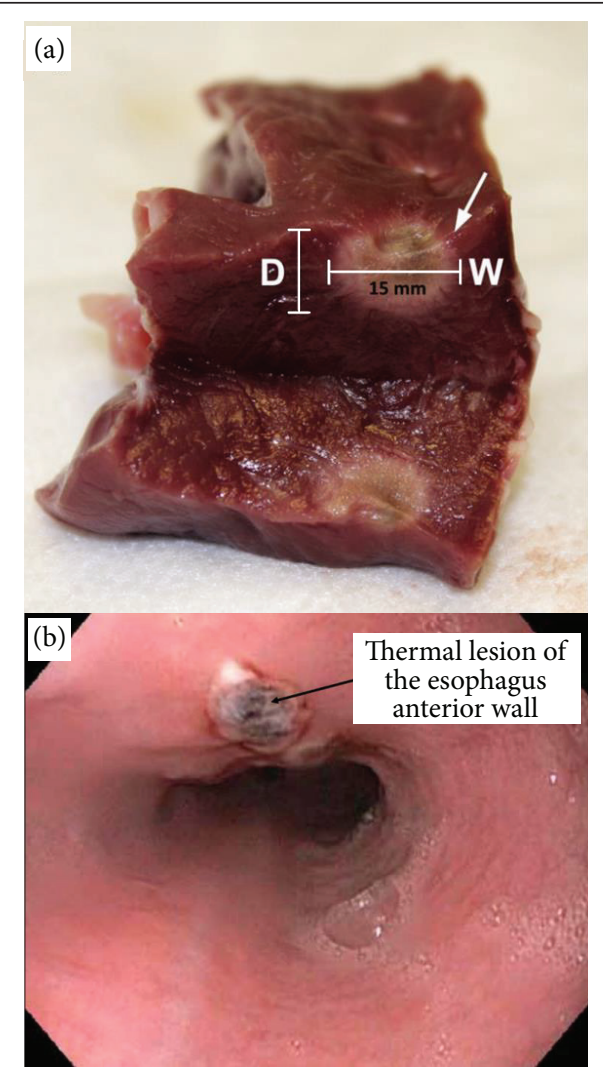

(a) Experimental study using pig's heart. It is observed that the lesion can reach a depth of 10 to $15 \mathrm{~mm}$, sufficient to cross the atrial wall and reach the esophagus. (b) Case in the literature showing a thermal lesion of the esophagus anterior wall seen by endoscopy from the lumen of the viscera in a 69-year-old patient complaining of dysphagia one day after ablation of the pulmonary veins. Fonte: (a) Calzolari et al.29; (b) Chavez et al. ${ }^{30}$.

Figure 2. Depth of thermal lesion from radiofrequency ablation. esophageal luminal temperature ${ }^{2,27,28}$. There is also a higher incidence of esophageal injury reported with robotic navigation compared to manual $\mathrm{AF}$ ablation using similar RF energy parameters ${ }^{18}$.

\section{ATRIOESOPHAGEAL FISTULA FORMATION MECHANISMS}

According to the current understanding, AEF is related to impairment of arterial blood supply due to occlusion of terminal arterioles, esophageal luminal infection and lesion of the anterior vagal plexus, which compromises the motility of the gastric antrum and the lower esophageal sphincter and, as a consequence, there is reflux of the gastric acid content ${ }^{2,18,28}$.

For Kapur et al. ${ }^{18}$, both the posterior wall of the LA and anterior wall of the esophagus may be compromised after RF application. Due to the lack of reports of perforation of the LA in the absence of esophageal lesion, it is inferred that the primary lesion (ulcer) occurs in the esophagus and progresses towards the posterior wall of the LA, determining the formation of the AEF.

The small number of reported cases of AEF has challenged physicians' ability to state which risk factors are most relevant. However, Halbfass et al. ${ }^{31}$ demonstrated for the first time a direct correlation between the thermal 
lesion of the esophagus, which occurs after AF ablation, and the perforation of this organ. The authors considered that thermal injury would be a prerequisite to trigger the series of events that determine the development of AEF and that a temperature $>40.5^{\circ} \mathrm{C}$ inside the esophagus is associated with a 2.1 times higher risk. On the other hand, so far there is no temperature variation value that guarantees that no thermal damage will occur.

\section{CLINICAL FEATURES}

Usually, the AEF diagnosis occurs between 2 days and 6 weeks after the ablation procedure. Han et al. ${ }^{32}$ described that patients with AEF usually present fever as an initial symptom in $73 \%$ of the cases, in addition to neurological symptoms (focal deficits, convulsions, mental confusion and loss of consciousness) in $72 \%$, gastrointestinal symptoms (hematemesis, melena, dysphagia, odynophagia, nausea and vomiting) in $41 \%$ and cardiac symptoms (chest pain, dyspnea and palpitations) in 40\%. In their multivariate analysis, indicators of mortality risk were: presence of neurological symptoms with a probability ratio (PR) of $16(\mathrm{p}<0.001)$ and presence of digestive bleeding, with PR of 4.22 ( $p<0.047)$.

Another complication described is gastroparesis, which is gastric obstruction due to the absence of a mechanical component ${ }^{33,34}$. These symptoms may begin within $3 \mathrm{~h}$ to 3 weeks after the ablation procedure has been performed. The mechanism of injury occurs through damage to the vagal plexus that compromises motility and gastric emptying.

\section{DIAGNOSIS}

It is very important to accurately diagnose the complications of AF ablation procedures, such as $\mathrm{EAF}$ and gastroparesis. First, when an EAF is being considered as a possible diagnosis, a white blood cells count is recommended because it is an early and sensitive laboratory marker of this complication. Blood cultures of patients with sepsis secondary to AEF usually develop gram-positive organisms ${ }^{18}$. Confirmation of the diagnosis is usually made by computed tomography (CT) or magnetic resonance imaging (MRI) with intravenous contrast (Fig. 3).
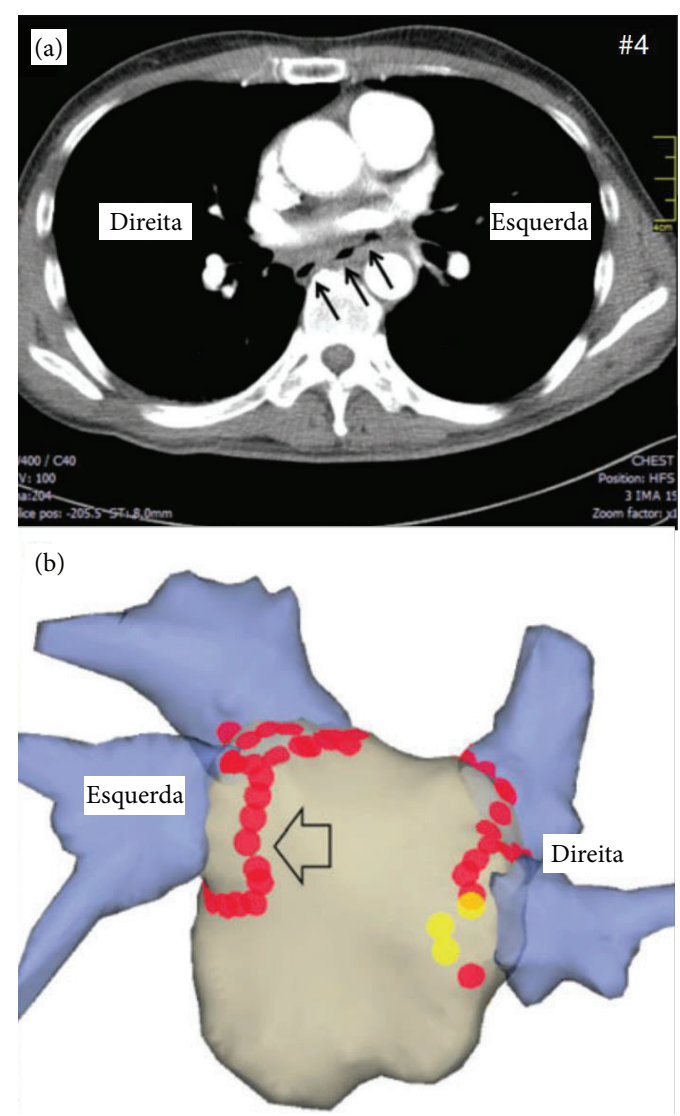

(a) Image of chest CT showing the presence of AEF outlined by air that propagates from the esophagus towards the left inferior pulmonary vein antrum (arrows); (b) Image of electroanatomic mapping (posterior view) obtained during ablation. The red dots identify the isolation lines around the pulmonary vein antrum. In this case, the region where the esophageal temperature increased (yellow dots) does not correspond to the region of the left atrium where the EAF was formed (larger arrow) confirming that the esophageal overlap is a more important factor than the measured temperature increase ${ }^{35}$.

Figure 3. Relation between RF applications and AEF formation.

In both cases, the initial phase of the examination may indicate the presence of a pneumomediastinum or pneumopericardium, while the contrast phase may also indicate contrast overflow between the LA and the mediastinum or between the LA and the esophagus. The use of oral contrast is recommended to complement a possible diagnosis of isolated esophageal rupture ${ }^{18}$.

It is important to keep in mind that procedures such as high digestive endoscopy (HDE), which manipulate the esophagus, should be avoided, so that the risk of massive air embolization due to insufflation of the esophagus is avoided. Secondly, if gastroparesis is suspected, when there are symptoms of delayed gastric emptying, the performance of methods such as scintigraphy or magnetic resonance imaging ${ }^{49}$ is recommended to confirm this delay. 


\section{TREATMENT}

Due to the low incidence of AEF, there are few studies that have significant statistical data supporting a therapy as the most effective. Nevertheless, during clinical practice, proton pump inhibitors, $\mathrm{H} 2$ inhibitors and sucralfate are widely used. They are prescribed a few days before the ablation procedure until 4 to 6 weeks after the procedure, mainly in cases where the lesion of the esophageal mucosa is identified ${ }^{36,37}$.

Once the diagnosis has been established, treatment should be carried out early. There are two techniques that can be used, correction with the use of endoscopic stenting or surgical correction, which is preferable because it significantly reduces the mortality rate ${ }^{13,20}$.

In a retrospective analysis with 29 patients presenting $\mathrm{AEF}$ after the AF ablation procedure, it was shown that $100 \%$ of the patients who were treated with stent died, while $59 \%$ of the patients who underwent the surgical procedure survived ${ }^{38}$.

In the case of a diagnosis of gastroparesis, depending on the degree of the lesion, treatment can be performed through diet modification and nutritional support, prokinetic agents, intrapiloric injection of botulinum toxin and also using gastric electrical stimulation. In these cases, positive results were reported within weeks ${ }^{38}$.

Patients should be well advised about the wide range of symptoms related to esophageal injury before discharge from hospital in order to anticipate possible diagnosis of complications.

\section{TECHNIQUES TO PREVENT OVERHEATING OF THE ESOPHAGUS}

Several techniques have been developed to provide greater safety during the application of $\mathrm{RF}$ to the posterior wall of the LA. Any technique used to limit or prevent the release of RF in areas close to the esophagus depends on precise information on the specific location of that organ in relation to the target areas for ablation. One of the greatest challenges is the wide anatomical variation of width and its constant mobility.

The ideal technique to avoid thermal esophageal lesions would be not to apply any RF in regions near the esophagus. However, there is often overlap between the posterior wall of the LA, PVs and the esophagus ${ }^{23}$. Such an approach would be less effective because it would not allow all the necessary RF energy to be applied in the overlapping regions, which could compromise the outcome of the ablative procedure. The images of the esophagus obtained before $\mathrm{AF}$ ablation are not reliable for this purpose because the natural mobility of this organ can alter its positioning at any time, that is, these images should be obtained in real time during ablation.

Stárek et al. ${ }^{39}$ demonstrated that only in $35 \%$ of the cases there was a correspondence between the position of the esophagus before and just after the ablation procedure. Daoud et al. ${ }^{40}$ also observed a modification of up to $50 \%$ in the esophageal diameter in $44 \%$ of the studied patients who underwent the AF ablation procedure. Under deep sedation and orally administered barium contrast, Good et al. ${ }^{41}$ obtained similar results: $67 \%$ of their patients had spontaneous lateral esophageal displacement $\geq 2 \mathrm{~cm}$ and $4 \%$ had displacement $\geq 4 \mathrm{~cm}$.

One of the methods used for esophageal visualization during fluoroscopy is the administration of barium contrast via oral or esophageal tube $(20-30 \mathrm{ml})$, which remains collected inside for 30-60 $\mathrm{min}^{39}$. Thus, using the radiological image, it is possible to visualize the position of the esophagus in relation to the LA in real time. The main limitation of this technique is that it does not allow to delimit the esophageal edges, because only its lumen is visualized. However, Stárek et al. ${ }^{39}$ demonstrated that there were no significant differences between esophageal diameters when these were evaluated by three-dimensional angiography and computed tomography.

Although this technique allows real-time esophageal visualization, it is not able to effectively prevent thermal damage if RF applications are made on this organ ${ }^{28}$.

\section{INTRACARDIAC ULTRASONOGRAPHY}

Intracardiac echocardiography (ICE), on the other hand, allows the visualization of the position of the esophagus in relation to the LA in real time. The delimitation of your borders with the integration of your images with the $3 \mathrm{D}$ electroanatomic mapping system is also possible and very useful. Moreover, it has the advantage of not using fluoroscopy to delimit the esophagus, it allows the 
evaluation of the regions of the esophagus that are in contact with the posterior wall of the LA, besides observing the distance between these two structures and the pattern of microbubbles formation, which can indicate atrial wall overheating $^{42}$. Even so, ICE does not allow the esophagus position to be changed if there is an overlap of a target area for ablation.

\section{Radiopaque esophagus delineation devices}

This technique can be performed through an esophageal thermometer or with electrophysiology catheters that can outline the luminous edges of the esophagus and its path approximately. A catheter can also be positioned in the esophageal lumen so that it is recognized by the $3 \mathrm{D}$ electroanatomic mapping system and thus virtually show the edges of the esophagus delimited by points ${ }^{43}$.

\section{Electroanatomical mapping combined with computed tomography or magnetic resonance imaging}

The use of computed tomography or magnetic resonance imaging before a procedure allows to generate images of the LA and esophagus. These images can be fused with the anatomy built by the $3 \mathrm{D}$ electroanatomic mapping system. This method has a restriction already mentioned before, because it generates static images ${ }^{39,44}$. Thus, changes in the position of the esophagus during the procedure may occur and may not be identified at the time of applying $\mathrm{RF}$ to the LA posterior wall. Consequently, a false sense of security can be produced during RF application.

\section{RF power titration (W)}

The most used technique in the various services of electrophysiology is the power titration applied to the posterior wall of the LA. Some authors recommend titration of RF power at $\leq 25 \mathrm{~W}$ and adjust the duration of $\mathrm{RF}$ application at $\leq 30 \mathrm{~s}^{28,37}$. According to Bahnson et al. ${ }^{43}$ it would be advisable to limit RF power to values below $20 \mathrm{~W}$ for 15 to $20 \mathrm{~s}$ in each application when close to the esophagus, and then wait at least $180 \mathrm{~s}$ for adequate organ cooling. However, more data is needed to support this approach.
The greatest challenges of this technique remain in knowing the precise location of the esophageal borders, as well as the safe amount of energy that is sufficient to generate a transmural atrial lesion without compromising the esophagus ${ }^{43}$. Therefore, RF power titration usually depends on the use of an esophageal thermometer that can help control the amount of power applied in these regions near the esophagus.

\section{Luminal esophageal temperature monitoring}

Continuous esophageal temperature monitoring is able to detect and provide alerts when there is an increase in luminal temperature during $\mathrm{RF}$ application. In the literature, there is no precise limit to the maximum temperature so that the application of RF can be stopped due to the risk of esophageal injury. Several researchers have already dealt with this problem. Some authors suggest maximum values between 39 and $41^{\circ} \mathrm{C}$, however, the incidence of esophageal lesions varies from 10 to $47 \%$ using these cutoff values ${ }^{12,45-47}$. Singh et al. ${ }^{49}$ demonstrated lower incidence of esophageal injury in comparison with not using a thermometer $(6 \%$ vs $36 \%$; $\mathrm{p}<0.006$ ), when using a cutoff point of $38.5^{\circ} \mathrm{C}$ to stop $\mathrm{RF}$ application. The increase $\geq 1{ }^{\circ} \mathrm{C}$ in relation to the basal esophageal temperature can be used as a cutoff criterion $^{37}$, however there are reports of esophageal lesions even with less warming ${ }^{52}$. In addition, at each elevation of $1{ }^{\circ} \mathrm{C}$ in relation to the esophageal basal temperature, there is an OR of 1.36 for the development of thermal damagee ${ }^{48}$.

Müller et al. ${ }^{49}$ evaluated a group of 80 patients by high digestive endoscopy (HDE) two days after AF ablation. The authors found evidence that the group in which the esophageal thermometer was used had a higher number of esophageal lesions when compared to the group that did not use it ( $30 \%$ vs. $2.5 \%, \mathrm{p}<0.01)$, and in multivariate logistic regression, the only independent risk predictor for the formation of esophageal lesions was the presence of the thermometer (PR 16.7, $\mathrm{p}<0.01$ ).

In a later publication, Halbfass et al. ${ }^{50}$ evaluated the risk of using an esophageal thermometer, now with electrical insulation in its temperature poles. The incidence of esophageal lesions was similar in the group with and without the device, respectively $(7.5 \%$ vs. $10 \%, \mathrm{p}=1.0)$. Thus, the authors concluded that the use of electrically isolated thermometers is not related to the increased risk 
of esophageal lesions. However, although there is reduction, thermal lesions are still described which demonstrate that this esophageal protection technique is not sufficient to prevent them.

\section{Continuous esophageal cooling}

One way to prevent the esophageal warming can be through intraesophageal balloon systems or by instilling intraluminal cold water. However, despite proper cooling of the mucosa, sufficient cooling of the outer portions of the esophageal wall is not guaranteed ${ }^{52,53}$. There is also a displacement of the esophagus in direction to the posterior wall of the LA after balloon insufflation, which, theoretically, may increase the risk of thermal damage.

\section{Mechanical deviation}

Considering that the esophagus is anatomically very close to the posterior wall of the LA, has a variable path and presents mobility in the posterior mediastinum, the possibility of moving this organ from regions with risk of heating using devices inserted in the esophageal lumen has arisen.

This technique idealized by Pachón et al. ${ }^{53}$ constitutes the contralateral mechanical deviation of the esophagus through the use of the transesophageal echocardiogram (TEE) transducer itself (Fig. 4). According to the region where RF is applied in the LA, the esophagus is moved laterally to the opposite position by manipulating the TEE transducer, obtaining, in the vast majority of cases, a sufficient distance to avoid heating this organ. In addition, a multichannel thermometer can be inserted into the esophageal lumen to monitor temperature during $\mathrm{RF}$ application ${ }^{55}$. If any temperature rise is found, the esophageal deviation is reassessed and optimized to allow the application in a safe and complete way. According to these studies, no cases of atrioesophageal fistula or major esophagusrelated complications were observed, and this technique was used in a large number of cases (704 patients) $)^{54}$.

Later, Chugh et al. ${ }^{55}$ also described the use of the technique, but performed the mechanical deviation of the esophagus with the TEE transducer and this device was later removed with the justification of possible antenna effect (effect by induction between transducer and RF catheter). In this condition, the esophagus returned to its basal position in 7 of the 9 cases, being ineffective.

More recently, in 2012, Koruth et al..$^{56}$ performed the mechanical bypass in 20 patients, using a pre-molded guide that was inserted by a nasogastric tube. Thus, the esophagus could be moved to safer regions, preventing or reducing its warming. According to the authors' investigation, the mean deviation was $2.8 \pm 1.6 \mathrm{~cm}$ to the left and $2.8 \pm 1.8 \mathrm{~cm}$ to the right. The authors described that the esophageal temperature reached $\geq 38.5^{\circ} \mathrm{C}$ in $3 / 20$ cases and in no patient was recorded above $40^{\circ} \mathrm{C}$. Of the 20 patients included, $63 \%$ had superficial esophageal lesions related to trauma, but without clinical repercussions.

Other manufacturers have developed systems capable of mechanically moving the esophagus away from its original position to a position away from the RF application site on the LA posterior wall (Fig. 6). Emphasis on EsoSure (Northeast Scientific Inc.) which is simply a nitinol metal wire with two preformed curves. These curves are soft at room temperature

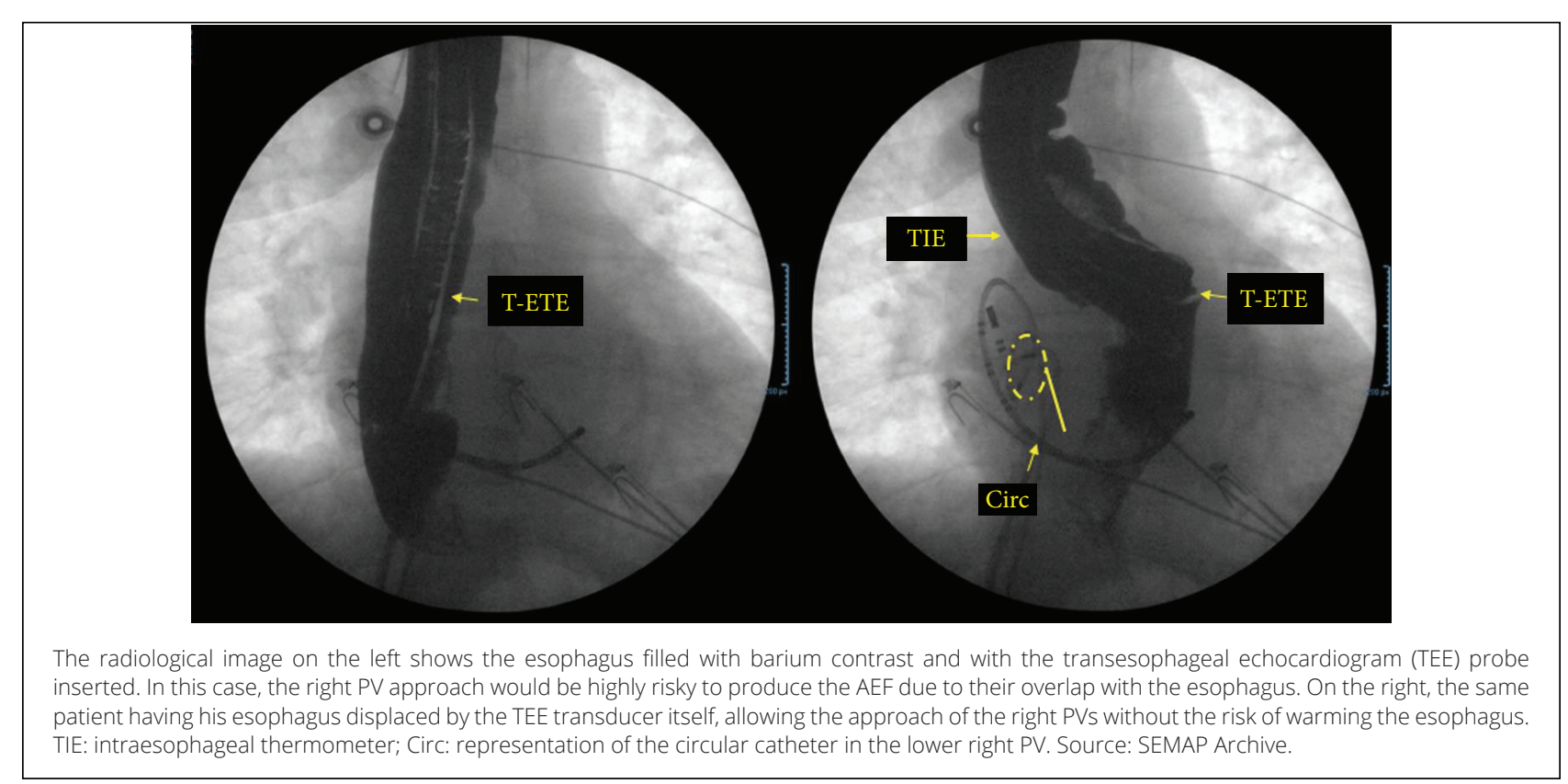

Figure 4. Technique designed by Pachón et al. ${ }^{53}$ to protect the esophagus during atrial fibrillation ablation. 
facilitating their introduction, but when heated with body temperature, they become very prominent promoting the displacement of the esophagus. The movement of the device allows you to choose the most suitable position according to where RF will be applied.

Another device created for the dislocation of the esophagus is called DV8 (Manual Surgical Sciences). It remains rectified in basal conditions allowing its insertion through the oral cavity. Subsequently an internal balloon is inflated, modifying the shape and allowing the displacement of the esophagus. To make it easier to visualize, one way allows to fill it with contrast guiding the level and the desired degree of displacement.

\section{DISCUSSION}

The proximity of the posterior wall of the LA to the esophagus is extremely relevant in the AF ablation scenario, and is not only an anatomical consideration. The antral and mainly circumferential approach of the PVs results in greater convergence of the blocking lines in the posterior wall of the LA. It is also possible that residual tachycardias appear after AF ablation, on the posterior wall of the LA, of the atypical flutter type and BKT.

Assuming that direct thermal damage to the esophagus is the probable pathophysiological mechanism of AEF, it is necessary to develop techniques that allow the application of the power and duration of RF necessary for the proper treatment of these critical regions and, at the same time, avoid heating the esophagus. Although there are several strategies available to prevent overheating of the esophagus by identifying its location; by reducing the amount or duration of RF energy supplied; by monitoring the temperature of the esophagus or by continuous cooling of the esophageal lumen. Nevertheless, it is possible to observe its overheating, and none of them modifies the position of the esophagus in order to avoid injury from the increase in temperature.
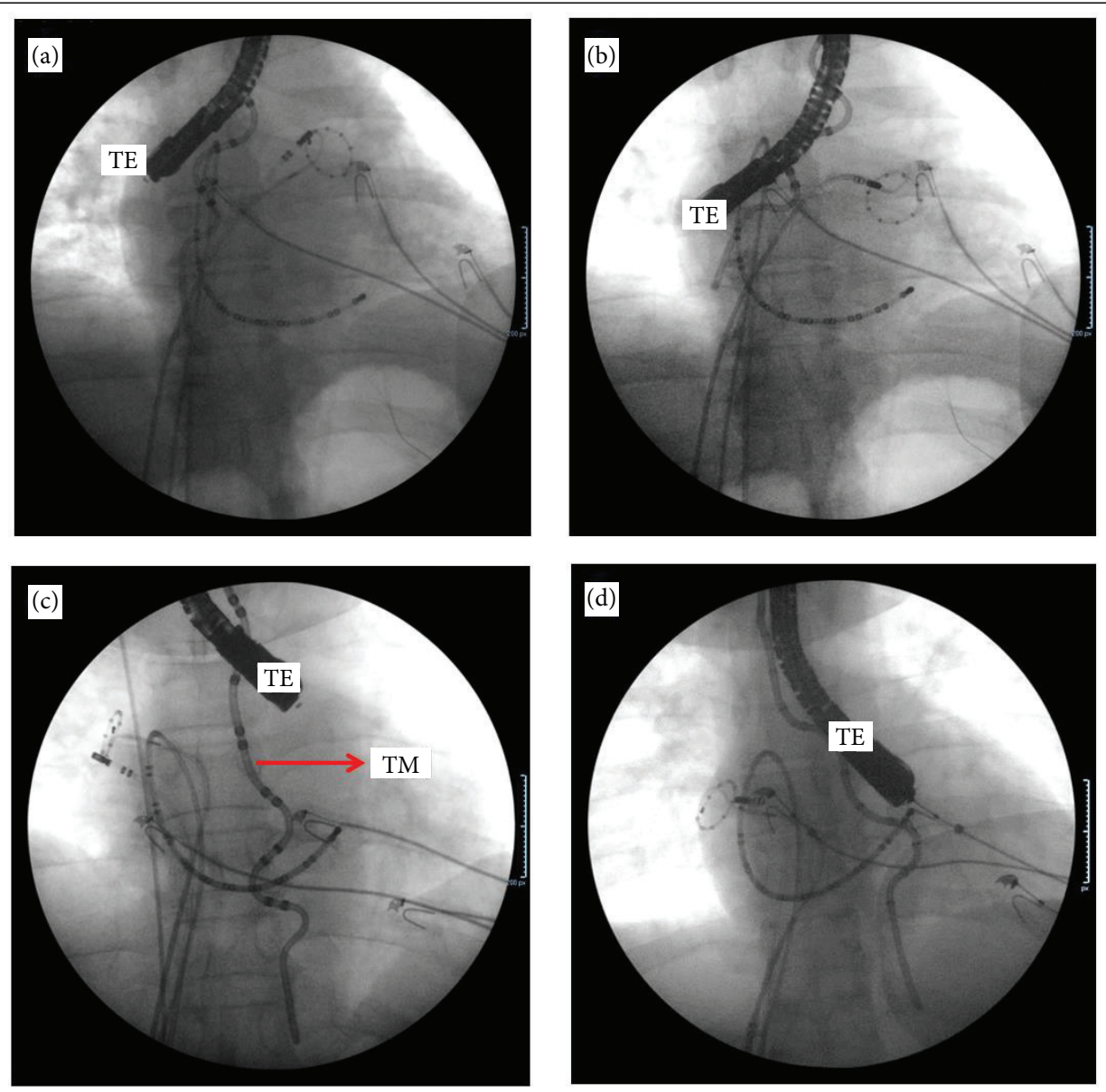

Using TEE transducer it is possible to move the esophagus away to address all PVs (A, B, C, D) without risk of esophageal warming. To prove safety, a multichannel thermometer (MT) (Circa) is also positioned in the esophageal light allowing confirmation that there has been complete displacement of the organ, and not only of its side wall, in addition to continuous monitoring of temperature. Source: SEMAP Archive.

Figure 5. Radiological images obtained during AF ablation procedure according to Pachón et al53 technique. 


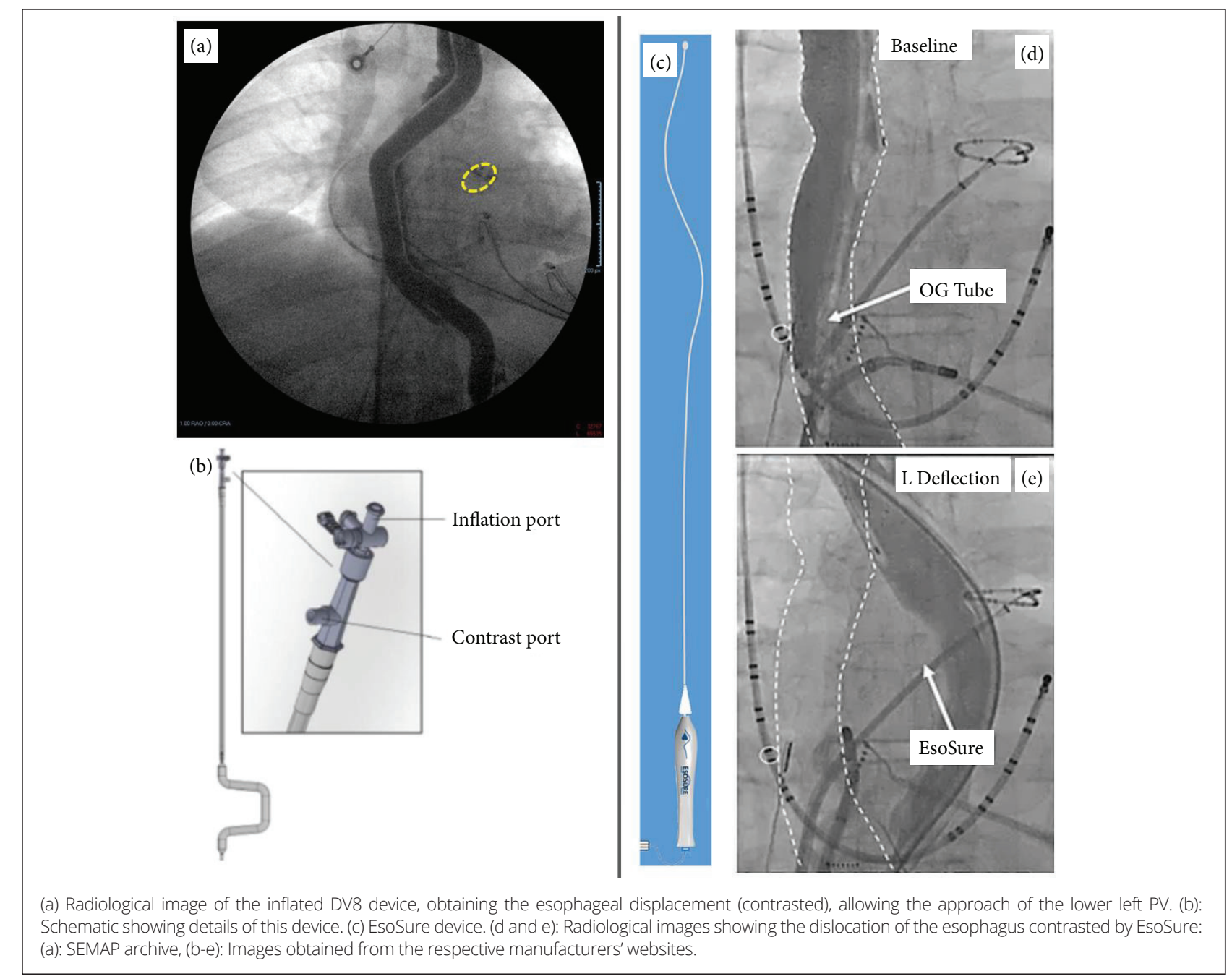

Figure 6. Images showing two commercially available devices for obtaining esophageal displacement during AF ablation.

In monitoring the temperature by intraesophageal thermometer, although very useful, one should consider the temperature of the esophageal mucosa, the innermost portion of the organ, which is being measured. When this temperature rises, the outer portions of the esophagus have already reached much higher values, compromising precisely the most sensitive areas, composed by irrigation and innervation. The temperature levels detected by this system should be drastically reduced to prevent external regions from reaching risk levels. In the technique developed by Pachón et al..$^{53}$, the intraesophageal thermometer emits an alert when the local temperature exceeds only $0.5^{\circ} \mathrm{C}$ of the body temperature and a powerful alarm if it reaches $1{ }^{\circ} \mathrm{C}$ above this value (Fig. 7) $)^{5,55}$. With such parameters, the external layers of the esophagus are submitted to small temperature variations, within the physiological range, not harmful to it. Another important data to be considered is that the thermometer sensors are peripherally positioned in a sine shaped probe in such a way that they are supported in the lateral portions of the esophagus, places closer to the antrum of the PVs, which are the most vulnerable points during AF ablation.

Until now, the mechanical displacement of the esophagus seems to be the most effective and simplest approach, as it allows to apply all the necessary RF to the posterior wall of the LA, without limitation of power, temperature or time. The use of general anesthesia to perform the AF ablation procedure is necessary for this technique to be applied, which can be considered a limitation depending on the electrophysiology center. The mere presence of TEE transducer in the esophageal lumen is considered a risk factor, since it is able to bring its anterior wall closer to the posterior wall of the LA, where RF applications are performed. In this technique, it is mandatory to make the mechanical deviation to a contralateral point, far from the $\mathrm{RF}$ application to ensure safety. According to previous 


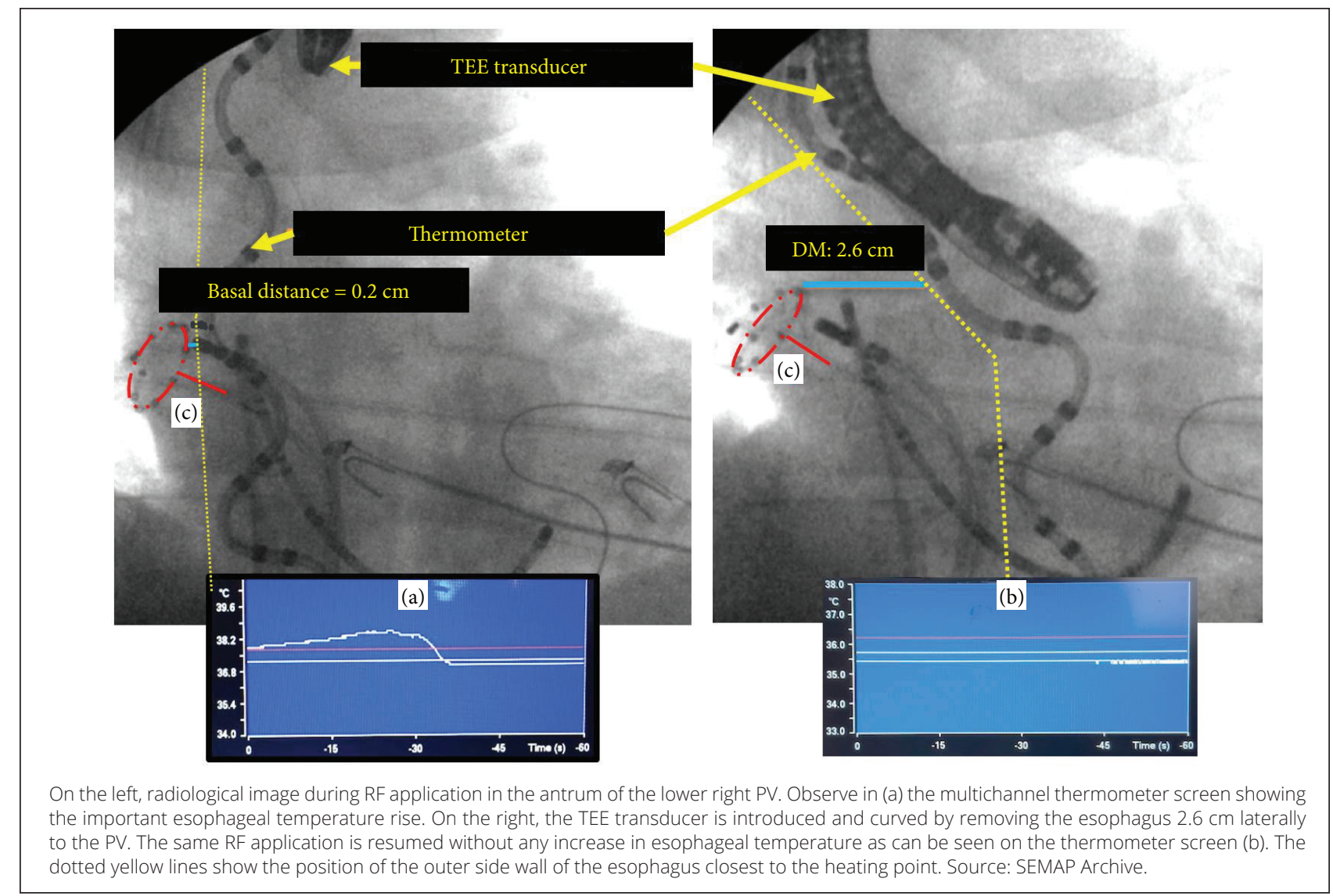

Figure 7. Efficiency of esophageal displacement by Pachón et al. ${ }^{53}$ technique.

publications by Pachón et al. ${ }^{53}$ and Koruth et al. ${ }^{56}$ this technique presented no major complications related to esophageal manipulation and no record of AEF.

Regarding a possible antenna effect (by electrical induction between the catheter tip and the esophageal thermometer), this was not demonstrated with the use of thermometers with electrical isolation of the sensors ${ }^{51}$. Apparently, this antenna effect was produced between the equipment that generates the $\mathrm{RF}$ and the equipment that measures the esophageal temperature, provided that both were not grounded at the same point, producing a difference in potential between them and allowing the RF to travel also through the poles of the thermometer (as if it were the dispersive electrode) causing injury at these contact sites. From the identification of this problem, some manufacturers of thermometers began to electrically isolate the thermal sensors and also added an auxiliary grounding to equal the potential between the two equipment, eliminating this problem. As for TEE transducer, this device is completely electrically isolated, and there is no exposed metal element (under normal conditions) that can produce the same antenna effect reported for thermometers. The TEE transducer also has a thermometer installed at the tip, used to monitor the temperature of the crystal that produces the ultrasound and to prevent its heating can damage the esophageal mucosa. When this crystal reaches a temperature of $38^{\circ} \mathrm{C}$, the equipment automatically turns off the TEE transducer to ensure patient safety. This thermometer is not suitable for monitoring esophageal temperature during $\mathrm{RF}$ application. It is important to point out that, in order to divert the esophagus, it is not necessary that this transducer is on, producing any heating.

\section{CONCLUSION}

The treatment of atrial fibrillation by radiofrequency has been showing great development since it was started in 1998 by Haïssaguerre. The complications that arose due to the procedure were each corrected by modifying the techniques and equipment used. The most feared complication is the atrioesophageal fistula, which, despite its low incidence, leads to death in almost all affected patients, despite the treatment instituted as soon as it is 
identified. Due to the high mortality, several authors have developed methods to protect the esophagus and reduce this complication.

The authors of this study developed a simple method of esophageal mechanical displacement using the transesophageal echocardiogram probe. This transducer is used to assess the presence of thrombi at the beginning of the procedure, to evaluate the presence of foramen ovale, to assist in the transseptal puncture, to accompany the entire procedure monitoring the presence of pericardial effusion and also to dislocate the esophagus at the time of application of radiofrequency in the antrum of each pulmonary vein, making the equipment extremely useful and safe in all stages of atrial fibrillation ablation.

More than 3,000 procedures have been performed with this method without a single atrioesophageal fistula, proving that the mechanical displacement of the esophagus is a highly simple, cheap and safe way to avoid this serious complication. Some manufacturers have presented solutions to perform esophageal diversion, which are available for services that do not routinely use transesophageal echocardiography during the procedure.

\section{REFERENCES}

1. Haïssaguerre $M$, Jaïs $P$, Shah DC, Takahashi $A$, Hocini $M$, Quiniou G, et al. Spontaneous initiation of atrial fibrillation by ectopic beats originating in the pulmonary veins. N Engl J Med, 1998;339(10):659-66. https://doi.org/10.1056/ NEJM199809033391003

2. Gerstenfeld EP, Guerra P, Sparks PB, Hattori K, Lesh MD. Clinical outcome after radiofrequency catheter ablation of focal atrial fibrillation triggers. J Cardiovasc Electrophysiol, 2001;12(8):9008. https://doi.org/10.1046/j.1540-8167.2001.00900.x

3. Haïssaguerre M, ShahDC, Jaïs P, Hocini M, YamaneT, Deisenhofer I, et al. Electrophysiological breakthroughs from the left atrium to the pulmonary veins. Circulation, 2000;102(20):2463-5. https://doi.org/10.1161/01.cir.102.20.2463

4. Noheria A, Kumar A, Wylie Jr JV, Josephson ME. Catheter ablation vs antiarrhythmic drug therapy for atrial fibrillation: a systematic review. Arch Int Med 2008;168(6):581-6. https://doi.org/10.1001/archinte.168.6.581

5. Nielsen JC, Johannessen A, Raatikainen P, Hindricks G, Walfridsson $\mathrm{H}$, Kongstad $\mathrm{O}$, et al. Radiofrequency ablation as initial therapy in paroxysmal atrial fibrillation. N Engl J Med, 2012;367:1587-95. https://doi.org/10.1056/NEJMoa1113566

6. Li WJ, Bai $Y Y$, Zhang HY, Tang RB, Miao CL, Sang $\mathrm{CH}$ et al. Additional ablation of complex fractionated atrial electrograms after pulmonary vein isolation in patients with atrial fibrillation: a meta-analysis. Circ Arrhythm Electrophysiol, 2011;4(2):143-8.

7. Pachon JCM, EIM Pachon, JCM Pachon, TJ Lobo, MZC Pachon, Vargas RNA, et al. "AF Nests" electrical resonance. Is it a new atrial fibrillation physiopathology? Heart Rhythm. 2005;2(5):S149. https://doi.org/10.1016/j.hrthm.2005.02.467

8. Mateos JCP, Mateos EIP, Lobo TJ, Pachón MZC, Mateos JCP, Pachón DQV, et al. Ablação da fibrilação atrial por cateter com radiofrequência guiada por mapeamento espectral endocárdico dos "ninhos de FA" em ritmo sinusal. Arq Bras Cardiol, 2007;89(3):140-50. https://doi.org/10.1590/ S0066-782X2007001500001
9. Mateos JCP, Mateos EIP, Santillana TGP, Lobo TJ, Pachón CTC, Mateos JCP, et al. Ablation of "background tachycardia" in long standing atrial fibrillation: improving the outcomes by unmasking a residual atrial fibrillation perpetuator. J Atr Fibrillation, 2017;10(2): 1583.

10. KnechtS, Hocini M, WrightM, Lellouche N, O'Neill MD, Matsuo S, et al. Left atrial linear lesions are required for successful treatment of persistent atrial fibrillation. Eur Heart J, 2008;29(19):2359-66. https://doi.org/10.1093/eurheartj/ehn302

11. Marrouche NF, Dresing T, Cole C, Bash D, Saad E, Balaban $K$, et al. Circular mapping and ablation of the pulmonary vein for treatment of atrial fibrillation: impact of different catheter technologies. J Am Coll Cardiol, 2002;40(3):464-74. https://doi.org/10.1016/s0735-1097(02)01972-1

12. Schmidt M, Nölker G, Marschang $H$, Gutleben $\mathrm{KJ}$, Schibgilla $\mathrm{V}$, Rittger $\mathrm{H}$, et al. Incidence of oesophageal wall injury postpulmonary vein antrum isolation for treatment of patients with atrial fibrillation. Europace 2008, 10(2):205-9. https:// doi.org/10.1093/europace/eun001

13. Chavez P, Messerli FH, Casso Dominguez A, Aziz EF, Sichrovsky T, Garcia D, et al. Atrioesophageal fistula following ablation procedures for atrial fibrillation: systematic review of case reports. Open Heart, 2015;2(1):e000257. https:// doi.org/10.1136/openhrt-2015-000257

14. Kottkamp $H$, Hindricks $G$, Autschbach R, Krauss B, Strasser B, Schirdewahn P, et al. Specific linear left atrial lesions in atrial fibrillation: Intraoperative radiofrequency ablation using minimally invasive surgical techniques. J Am Coll Cardiol, 2002;40(3):475-80. https://doi.org/10.1016/S07351097(02)01993-9

15. Yousuf $T$, Keshmiri H, Bulwa Z, Kramer J, Arshad HMS, Issa $\mathrm{R}$, et al. Management of atrio-esophageal fistula following left atrial ablation. Cardiol Res. 2016;7(1):36-45. https://doi. org/10.14740/cr454e

16. Calkins H, Kuck KH, Cappato R, Brugada J, Camm AJ, Chen SA, et al. 2012 HRS/EHRA/ECAS expert consensus statement on catheter and surgical ablation of atrial 
fibrillation: recommendations for patient selection, procedural techniques, patient management and followup, definitions, endpoints, and research trial design. J Interv Card Electrophysiol, 33, 171-257 (2012). https://doi. org/10.1007/s10840-012-9672-7

17. Vasconcelos JTM, Galvão Filho SS, Atié J, Maciel W, Souza OF, Saad EB, et al. Atrial-oesophageal fistula following percutaneous radiofrequency catheter ablation of atrial fibrillation: the risk still persists. EP Europace, 2017;19(2):2508. https://doi.org/10.1093/europace/euw284

18. Kapur S, Barbhaiya C, Deneke T, Michaud GF. Esophageal injury and atrioesophageal fistula caused by ablation for atrial fibrillation. Circulation, 2017;136(13):1247-55. https:// doi.org/10.1161/CIRCULATIONAHA.117.025827

19. Cappato R, Calkins H, Chen SA, Davies W, lesaka Y, Kalman J, et al. Prevalence and causes of fatal outcome in catheter ablation of atrial fibrillation. J Am Coll Cardiol, 2009;53(19):1798-803. https://doi.org/10.1016/j.jacc.2009.02.022

20. Nair GM, Nery PB, Redpath CJ, Lam BK, Birnie DH. Atrioesophageal fistula in the era of atrial fibrillation ablation: a review. Can J Cardiol, 2014;30(4):388-95. https:// doi.org/10.1016/j.cjca.2013.12.012

21. Barbhaiya CR, Kumar S, Guo Y, Zhong J, John RM, Tedrow UB. Global survey of esophageal injury in atrial fibrillation ablation: characteristics and outcomes of esophageal perforation and fistula. JACC Clin Electrophysiol. 2016;2(2):143-50. https:// doi.org/10.1016/j.jacep.2015.10.013

22. Vijayaraman P, Netrebko P, Geyfman V, Dandamudi G, Casey K, Ellenbogen KA. Esophageal fistula formation despite esophageal monitoring and low-power radiofrequency catheter ablation for atrial fibrillation. Circ Arrhythmia Electrophysiol, 2009;2(5):e31-3. https://doi.org/10.1161/CIRCEP.109.883694

23. Jang SW, Kwon BJ, Choi MS, Kim DB, Shin WS, Cho EJ et al. Computed tomographic analysis of the esophagus, left atrium, and pulmonary veins: implications for catheter ablation of atrial fibrillation. J Interv Card Electrophysiol, 2011;32(1):1-6. https://doi.org/10.1007/s10840-011-9594-9

24. Maeda S, lesaka Y, Uno K, Otomo K, Nagata Y, Suzuki K, et al. Complex anatomy surrounding the left atrial posterior wall: analysis with 3D computed tomography. Heart Vessels, 2012;27(1):58-64. https://doi.org/10.1007/s00380-011-0120-x

25. Cury RC, Abbara S, Schmidt S, Malchano ZJ, Neuzil P, Weichet $J$, et al. Relationship of the esophagus and aorta to the left atrium and pulmonary veins: Implications for catheter ablation of atrial fibrillation. Heart Rhythm 2005 Dec;2(12):1317-23. https://doi.org/10.1016/j.hrthm.2005.09.012

26. Ueno T, Uemura K, Harris MB, Pappas TN, Takahashi T. Role of vagus nerve in postprandial antropyloric coordination in conscious dogs. Am J Physiol Gastrointest Liver Physiol. 2005;288(3):G487-95. https://doi.org/10.1152/ ajpgi.00195.2004

27. Nair KKM, Danon A, Valaparambil A, Koruth JS, Singh SM. Atrioesophageal fistula: a review J Atr Fibrillation. 2015 OctNov; 8(3):1331.
28. Martinek M, Bencsik G, Aichinger J, Hassanein S, Schoefl R, Kuchinka P, et al. Esophageal damage during radiofrequency ablation of atrial fibrillation: impact of energy settings, lesion sets, and esophageal visualization. J Cardiovasc Electrophysiol, 2009 Jul;20(7):726-33. https:// doi.org/10.1111/j.1540-8167.2008.01426.x

29. Calzolari V, Mattia L, Indiani S, Crosato M, Furlanetto A, Licciardello $C$, et al. In vitro validation of the lesion size index to predict lesion width and depth after irrigated radiofrequency ablation in a porcine model. JACC Clin Electrophysiol, 2017;3(10):1126-35. https://doi. org/10.1016/j.jacep.2017.08.016

30. Chavez P, Messerli FH, Casso Dominguez A, Aziz EF, Sichrovsky T, Garcia D, et al. Atrioesophageal fistula following ablation procedures for atrial fibrillation: systematic review of case reports. Open Heart, 2015;2(1):e000257. https:// doi.org/10.1136/openhrt-2015-000257

31. Halbfass P, Pavlov B, Müller P, Nentwich K, Sonne K, Barth $S$, et al. Progression from esophageal thermal asymptomatic lesion to perforation complicating atrial fibrillation ablation: a single-center registry. Circ Arrhythm Electrophysiol, 2017;10(8):e005233. https://doi.org/10.1161/ CIRCEP.117.005233

32. Han HC, Ha FJ, Sanders P, Spencer R, Teh AW, O'Donnell D, et al. Atrioesophageal fistula clinical presentation, procedural characteristics, diagnostic investigations, and treatment outcomes. Circ Arrhythm Electrophysiol, 2017;10:e005579. https://doi.org/10.1161/CIRCEP.117.005579

33. Linz D, Hohl M, Vollmar J, Ukena C, Mahfoud F, Böhm M. Atrial fibrillation and gastroesophageal reflux disease: the cardiogastric interaction. Europace. 2017;19(1):16-20. https://doi.org/10.1093/europace/euw092

34. Garg L, Garg J, Gupta N, Shah N, Krishnamoorthy P, Palaniswamy C, et al. Gastrointestinal complications associated with catheter ablation for atrial fibrillation. Int J Cardiol, 2016;224:424-30. https://doi.org/10.1016/j.ijcard.2016.09.069

35. Vasconcelos JTM, Galvão Filho SS, Atié J, Maciel W, Souza OF, Saad EB, et al. Atrial-oesophageal fistula following percutaneous radiofrequency catheter ablation of atrial fibrillation: the risk still persists. Europace. 2017;19(2):25058. https://doi.org/10.1093/europace/euw284

36. January CT, Wann LS, AlpertJS, Calkins H, CigarroaJE, Cleveland Jr JC, et al. 2014 AHA/ACC/HRS guideline for the management of patients with atrial fibrillation: executive summary: a report of the American College of Cardiology/American Heart Association Task Force on practice guidelines and the Heart Rhythm Society.. Circulation. 2014;130(23):2071-104. https:// doi.org/10.1161/CIR.0000000000000040

37. Scanavacca M. Ablação de FA e risco de lesão esofágica. Arq Bras Cardiol, 2016;106(5):354-7.

38. Singh SM, d'Avila A, Singh SK, Stelzer P, Saad EB, Skanes $A$, et al. Clinical outcomes after repair of left atrial esophageal fistulas occurring after atrial fibrillation ablation procedures. Heart Rhythm, 2013;10(11):1591-7. https:// doi.org/10.1016/j.hrthm.2013.08.012 
39. Stárek Z, Lehar F, Jež J, Žbánková A, Kulík T, Wolf J, Novák M. Long-term mobility of the esophagus in patients undergoing catheter ablation of atrial fibrillation: data from computer tomography and 3D rotational angiography of the left atrium. J Interv Card Electrophysiol, 2016; 46(2):81-7. https://doi.org/10.1007/s10840-016-0121-x

40. Daoud EG, Hummel JD, Houmsse M, Hart DT, Weiss R, Liu Z, et al. Comparison of computed tomography imaging with intraprocedural contrast esophagram: implications for catheter ablation of atrial fibrillation. Heart Rhythm. 2008;5(7):975-80. https://doi.org/10.1016/j.hrthm.2008.03.058

41. Good E, Oral H, Lemola K, Han J, Tamirisa K, Igic P, et al. Movement of the esophagus during left atrial catheter ablation for atrial fibrillation. J Am Coll Cardiol, 2005;46(11):2107-10. https://doi.org/10.1016/j.jacc.2005.08.042

42. Bunch TJ, May HT, Crandall BG, Weiss JP, Bair TL, Osborn JS, et al. Intracardiac ultrasound for esophageal anatomic assessment and localization during left atrial ablation for atrial fibrillation. J Cardiovasc Electrophysiol, 2013;24(1):339. https://doi.org/10.1111/j.1540-8167.2012.02441.x

43. Bahnson TD. Strategies to minimize the risk of esophageal injury during catheter ablation for atrial fibrillation. Pacing Clin Electrophysiol, 2009;32(2):248-60. https://doi. org/10.1111/j.1540-8159.2008.02210.x

44. Lemola K, Sneider M, Desjardins B, Case I, Han J, Good E, et al. Computed tomographic analysis of the anatomy of the left atrium and the esophagus: implications for left atrial catheter ablation. Circulation, 2004;110(24):3655-60. https://doi.org/10.1161/01.CIR.0000149714.31471.FD

45. Contreras-Valdes FM, Heist EK, Danik SB, Barrett CD, Blendea $D$, Brugge WR, et al. Severity of esophageal injury predicts time to healing after radiofrequency catheter ablation for atrial fibrillation. Heart Rhythm, 2011;8(12):1862-6. https:// doi.org/10.1016/j.hrthm.2011.07.022

46. Di Biase L, Dodig M, Saliba W, Siu A, Santisi J, Poe S, et al. Capsule endoscopy in examination of esophagus for lesions after radiofrequency catheter ablation: a potential tool to select patients with increased risk of complications. J Cardiovasc Electrophysiol, 2010;21(8):839-84. https://doi. org/10.1111/j.1540-8167.2010.01732.x

47. Halm U, Gaspar T, Zachäus M, Sack S, Arya A, Piorkowski C, et al. Thermal esophageal lesions after radiofrequency catheter ablation of left atrial arrhythmias. Am J Gastroenterol, 2010;105(3):551-6. https://doi.org/10.1038/ajg.2009.625

48. Singh SM, d'Avila A, Doshi SK, Brugge WR, Bedford RA, Mela $T$, et al. Esophageal injury and temperature monitoring during atrial fibrillation ablation. Circ Arrhythm Electrophysiol, 2008;1(3):162-8. https://doi.org/10.1161/ CIRCEP.107.789552

49. Müller P, Dietrich JW, Halbfass P, Abouarab A, Fochler F, Szöllösi A, et al. Higher incidence of esophageal lesions after ablation of atrial fibrillation related to the use of esophageal temperature probes. Heart Rhythm, 2015;12(17):1464-9. https://doi.org/10.1016/j.hrthm.2015.04.005

50. Halbfass P, Müller P, Nentwich K, Krug J, Roos M, Hamm K, et al. Incidence of asymptomatic oesophageal lesions after atrial fibrillation ablation using an oesophageal temperature probe with insulated thermocouples: a comparative controlled study. Europace, 2017;19(3):385-91. https://doi. org/10.1093/europace/euw070

51. Kuwahara T, Takahashi A, Okubo K, Takagi K, Yamao K, Nakashima $E$, et al. Oesophageal cooling with ice water does not reduce the incidence of oesophageal lesions complicating catheter ablation of atrial fibrillation: randomized controlled study. Europace, 2014;16(6):834-9. https://doi.org/10.1093/europace/eut368

52. Arruda MS, Armaganijan L, Di Biase L, Rashidi R, Natale A. Pre clinical "in vivo" evaluation of an esophageal protective system: implications on esophageal thermal injury during AF ablation. Heart Rhythm, 2008;5:S16. https://doi. org/10.1016/j.hrthm.2008.03.040

53. Pachón JCM, Mateos El, Peña TG, Lobo TJ, Mateos JC, Vargas RN. Simplified method for esophagus protection during radiofrequency catheter ablation of atrial fibrillation - prospective study of 704 cases. Rev Bras Cir Cardiovasc, 2015;30(2):139-47. https://doi.org/10.5935/1678-9741.20150009

54. Amarante RC. Eficácia e segurança da técnica do desvio mecânico na prevenção do aquecimento do esôfago na ablação da fibrilação atrial com cateter por radiofrequência. São Paulo. Tese [Doutorado em Ciências] - Universidade de São Paulo; 2019.

55. Chugh A, Rubenstein J, Good E, Ebinger M, Jongnarangsin K, Fortino J, et al. Mechanical displacement of the esophagus in patients undergoing left atrial ablation of atrial fibrillation. Heart Rhythm, 2009;6(3):319-22. https://doi.org/10.1016/j. hrthm.2008.12.010

56. Koruth JS, Reddy VY, Miller MA, Patel KK, Coffey JO, Fischer A, et al. Mechanical esophageal displacement during catheter ablation for atrial fibrillation. J Cardiovasc Electrophysiol, 2012;23(2):14754. https://doi.org/10.1111/j.1540-8167.2011.02162.x 